\title{
OS JOGOS TRADICIONAIS DO POVO KRAHÔ: CONSIDERAÇÕES DA IMERSÃO NA ALDEIA INDÍGENA MANOEL ALVES PEQUENO NO ESTADO DO TOCANTINS
}

\section{Paulo Hernandes Gonçalves da Silva ${ }^{1}$ Francisco Edviges Albuquerque ${ }^{2}$}

Resumo: A língua Indígena Krahô, pertencente à família linguística Jê, do Tronco Macro-Jê, é falada por, aproximadamente, 3.118 pessoas, distribuídas em 29 aldeias, situadas entre os municípios de Goiatins e Itacajá, no estado do Tocantins, conforme o Distrito Sanitário Especial Indígena. (DSEI/TO, 2016). Para a preservação de identidade, são realizados anualmente os Jogos Tradicionais Indígenas, com sua terceira edição em 2016. Esta pesquisa apresenta a estrutura da aldeia indígena Manoel Alves Pequeno (local dos jogos), descreve as modalidades praticadas e faz relato sobre a língua e a cultura Krahô, percebida na imersão, no período de 16 a 22/08/2016, por meio da parceria entre o Laboratório de Línguas Indígenas (LALI), da Universidade Federal do Tocantins (UFT) e o Campus Colinas do Instituto Federal do Tocantins (IFTO). Metodologicamente, no estudo, foram utilizadas a observação e a revisão de literatura, com os pressupostos de estudiosos do assunto, com destaque para Albuquerque (2013), Araújo (2015), Santos (2015) e Bortoni-Ricardo (2010).

Palavras-chave: Cultura indígena; Jogos; Língua; Povo Krahô.

\footnotetext{
1 Pós-graduando (aluno-especial) do componente de Sociolinguística no Programa de Doutorado da Universidade Federal do Tocantins, Mestre em Gestão e Desenvolvimento Regional pela UNITAU/SP e Professor de Letras do Instituto Federal do Tocantins - Campus Colinas, Brasil. E-mail: paulohg@ifto.edu.br.

${ }^{2}$ Doutor em Letras pela Universidade Federal Fluminense e Professor do Programa de Pós-graduação em Letras da Universidade Federal do Tocantins - Campus Araguaína, Brasil. E-mail: fedviges@uol.com.br.
} 